\title{
EFFECT OF INTRAVENOUS CLONIDINE ON PRESSOR RESPONSE TO LARYNGOSCOPY AND INTUBATION AND INDUCTION DOSE OF PROPOFOL
}

\author{
Harpriya Kaur 1 , Madhu Gupta², Divya Sethi ${ }^{3}$ \\ ${ }_{1}^{1}$ Senior Resident, Department of Anaesthesia, ESIPGIMSR, New Delhi. \\ 2Professor, Department of Anaesthesia, ESIPGIMSR, New Delhi. \\ ${ }^{3}$ Assistant Professor, Department of Anaesthesia, ESIPGIMSR, New Delhi.
}

\begin{tabular}{l}
\hline ABSTRACT \\
BACKGROUND \\
Sympathoadrenal response to laryngoscopy and intubation under general anaesthesia can cause profound haemodynamic \\
alterations, which at times can cause adverse myocardial events, especially in patients with reduced myocardial reserve and \\
associated cardiovascular comorbidities. Various medications are used to suppress this reflex in such patients. We studied the \\
effect of clonidine on this reflex and its effect on propofol consumption during induction of general anaesthesia.
\end{tabular}

\section{MATERIALS AND METHODS}

After permission from Hospital Ethics Committee, sixty ASA Class I and II patients were divided into two groups. Study group was given intravenous clonidine twenty minutes before induction and control group given intravenous normal saline under similar circumstances. Baseline haemodynamic parameters were recorded in both the groups and then after 5 minutes till 20 minutes after the start of infusion. After the induction of anaesthesia with propofol, haemodynamic parameters were recorded in both the groups every minute till five minutes after intubation of the patient. Consumption of propofol in both the groups was also recorded.

\section{RESULTS}

Baseline haemodynamic parameters and parameters after drug infusion in both groups are comparable. After induction of general anaesthesia, laryngoscopy and intubation, the haemodynamic parameters in control group have a significant $(p<0.001)$ elevation compared to study group. Study group shows a significantly lower consumption $(\mathrm{p}<0.001)$ of propofol compared to control group.

\section{CONCLUSION}

Premedication with intravenous clonidine prevents haemodynamic response during laryngoscopy and intubation and significantly reduces propofol requirements for induction of anaesthesia in healthy subjects without inducing adverse effects on haemodynamic stability.

\section{KEYWORDS}

Clonidine, Laryngoscopy, Propofol Consumption, Haemodynamic Parameters.

HOW TO CITE THIS ARTICLE: Kaur H, Gupta M, Sethi D. Effect of intravenous clonidine on pressor response to laryngoscopy and intubation and induction dose of propofol. J. Evolution Med. Dent. Sci. 2017;6(15):1167-1170, DOI: 10.14260/Jemds/2017/254

\section{BACKGROUND}

Sympathoadrenal response to laryngoscopy and endotracheal intubation though transient manifests as variable increase in heart rate and blood pressure. This sympathoadrenal response may be well tolerated in ASA 1 and II patients, but may cause myocardial instability in patients with limited cardiac reserve due to any reason.1,2,3,4,5 Intravenous and inhalational anaesthetic agents decrease the sympathetic response, but in variable manner. ${ }^{6}$

Clonidine an alpha-2 adrenergic agonist decreases central sympathetic tone and has intrinsic analgesic and sedative effect. Premedication with clonidine causes improved intraoperative haemodynamic stability, attenuates sympathoadrenal response to laryngoscopy and reduces requirement of anaesthetic agents. $7,8,9$

Financial or Other, Competing Interest: None.

Submission 13-01-2017, Peer Review 07-02-2017,

Acceptance 10-02-2017, Published 20-02-2017.

Corresponding Author:

Dr. Harpriya Kaur,

R/o. H. No. 22, St. No.2

Gopal Nagar, Majitha Road,

Amritsar-143001, Punjab.

E-mail: drharpriya@rediffmail.com

DOI: $10.14260 /$ jemds $/ 2017 / 254$
We studied the effectiveness of intravenous clonidine as to attenuate the haemodynamic responses to laryngoscopy and intubation and its effect on dose requirement of propofol for induction of general anaesthesia.

\section{MATERIALS AND METHODS}

After approval from Hospital Ethics Committee and informed consent, sixty patients of ASA Grade I and II adult patients were randomised into two groups of 30 patients each. Patients having hypertension, coronary artery disease, renal or cerebral disease, endocrine disorder, potential difficult airway, substance abuse and drug allergy were excluded from the study.

Patients were randomly allocated to control group ( $\mathrm{n}=$ 30 ) or clonidine group ( $\mathrm{n}=30)$ using computer generated list. Patients in clonidine group were given an infusion of IV clonidine hydrochloride $3 \mathrm{mcg} / \mathrm{kg}$ in $100 \mathrm{~mL}$ of normal saline and control group was given $100 \mathrm{~mL}$ of normal saline over 10 minutes in preoperative holding area. Baseline Heart Rate (HR), Systolic Blood Pressure (SBP), Diastolic Blood Pressure (DBP), Mean Arterial Pressure (MBP) and Oxygen Saturation (Sp02) were recorded and then at 5 mins ( $\mathrm{Z} 0)$, at 10 mins ( $\mathrm{Z}$ 1) and 20 mins after start of infusion (Z 3). 
In OR after attaching all monitors (ECG, NIBP, Sp02), fentanyl $1 \mathrm{mcg} / \mathrm{kg}$ IV was given and anaesthesia induced with propofol (1\%) given at rate of $0.5 \mathrm{~mL} / \mathrm{sec}$ till loss of patient's verbal response. This was taken as the endpoint of induction. Rocuronium bromide $0.9 \mathrm{mg} / \mathrm{kg}$ IV was given for muscle relaxation followed 1 min later by laryngoscopy and tracheal intubation by trained anaesthesiologist unaware of the group within less than $30 \mathrm{sec}$.

Haemodynamic parameters (HR, SBP, DBP, MBP, SpO2) at the time of laryngoscopy (Z 4), after ETT cuff inflation (Z 5) were recorded and at $1 \mathrm{~min}$ interval for subsequent 5 minutes after intubation ( $\mathrm{Z}$ 6-10). The haemodynamic parameters (HR, SBP, DBP, MBP, SpO2) were then recorded at 5 minutes interval till recovery from anaesthesia.

Anaesthesia for the surgery was maintained with N20, 02 and isoflurane (titrated to MAC 1\%) with intermittent positive pressure ventilation. At the end of surgery, neuromuscular blockade was reversed with neostigmine 50 $\mathrm{mcg} / \mathrm{kg}$ and glycopyrrolate $10 \mathrm{mcg} / \mathrm{kg}$, the trachea was extubated and the patient was shifted to Post Anaesthesia Care Unit.

The patient was monitored in post-operative recovery for 24 hours before being shifted to ward. The occurrence of any of the side effects like hypotension, bradycardia, hypertension, tachycardia, skin rash, bradypnoea or apnoea intraoperatively or in the $24 \mathrm{hrs}$. post-operative period was recorded.

\section{RESULTS}

Categorical variables were presented in number and percentage (\%) and continuous variables were presented as mean \pm SD. Quantitative variables were compared using unpaired t-test between the two groups. Qualitative variables were compared using Chi-Square test. A $p$ value of $<0.05$ was considered statistically significant. The data was entered in MS-Excel spreadsheet and analysis was done using Statistical Package for Social Sciences (SPSS) version 21.0.

The two groups were comparable with respect to demographic characteristics (Table 1). The haemodynamic parameters (HR, SBP, DBP, MBP) were comparable between the two groups at baseline (Z0), at 5 mins of start of infusion (Z 1), at 10 mins i.e. end of infusion ( $Z$ 2) and 20 mins after giving the infusion ( $Z$ 3). The HR, SBP, DBP and MBP were significantly lower for clonidine group compared to control group at the time of laryngoscopy ( $\mathrm{Z} 4$ ), after ETT cuff inflation ( $\mathrm{Z}$ 5) and for subsequent 5 minutes after intubation ( $\mathrm{Z} 6-10)(\mathrm{P}<0.001)$. On analysis of the trend of haemodynamic variables within each group, a statistically significant rise was observed in HR, SBP, DBP and MBP after laryngoscopy (Z4), ETT cuff inflation (Z 5) and for subsequent 5 minutes (Z 6-10) in the control group. In contrast to this, a statistically significant decline in HR, SBP, DBP and MBP was seen at the time of laryngoscopy (Z 4), after ETT cuff inflation (Z 5) and for subsequent 5 minutes after intubation (Z 6-10) in the clonidine group $(\mathrm{P}<0.001)$.

The mean heart rate in Group I was less than the baseline and showed a statistically significant decrease $(p<0.001)$ after laryngoscopy and remained stable after laryngoscopy and intubation for 5 minutes. The mean heart rate in Group II showed a significant rise after laryngoscopy and remained so even after five minutes of cuff inflation (Table 2). It was observed that SBP in Group I is less than the Group II 20 mins after completion of infusion. The systolic blood pressure in Group I showed a statistically significant decrease ( $p<0.001)$ after laryngoscopy and intubation. The mean SBP remained stable for 5 mins after intubation and showed a statistically significant difference $(\mathrm{p}<0.001)$ even after five minutes as compared to Group II (Table 3).

From Table 4, it can be concluded that diastolic blood pressure remained less than the baseline value in Group I during laryngoscopy and intubation. Mean diastolic blood pressure exceeded the baseline after laryngoscopy and intubation in Group II. On intergroup comparison, there was a very highly significant $(p<0.001$ ) change in DBP after laryngoscopy and intubation and similar trend was observed 5 minutes after intubation in both the groups. There was a fall in MAP (Table 5) 20 mins after premedication in Group I. The MAP in Group I was less than the baseline values even after laryngoscopy and intubation and the same trend was seen after 5 minutes of intubation. On intergroup comparison, it was observed that difference in two groups is highly significant $(\mathrm{p}<0.001)$. Propofol dose in clonidine group was significantly lower ( $\mathrm{p}<0.001)$ than control group $(94.5 \pm$ 11.17 vs. $124.5 \pm 10.10$ ).

\begin{tabular}{|c|c|c|c|}
\hline & Group I (n = 30) & Group II (n = 30) & \multirow{2}{*}{ P value } \\
\cline { 2 - 3 } & Mean \pm S.D & Mean \pm S.D & \\
\hline Age & $37.13 \pm 6.82$ & $39.3 \pm 7.72$ & 0.254 \\
\hline Weight & $55.3 \pm 8.61$ & $57.7 \pm 7.76$ & 0.261 \\
\hline
\end{tabular}

Table 1. Age and Weight Distribution in Two Groups

\begin{tabular}{|c|c|c|c|}
\hline \multirow{2}{*}{$\begin{array}{c}\text { Heart } \\
\text { Rate }\end{array}$} & Group I (n = 30) & Group II (n = 30) & \multirow{2}{*}{ P value } \\
\cline { 2 - 3 } & Mean \pm S.D & Mean \pm S.D & \\
\hline Z0 & $81.47 \pm 6.26$ & $79.73 \pm 3.85$ & 0.202 \\
\hline Z1 & $81.37 \pm 5.38$ & $79.27 \pm 4.79$ & 0.116 \\
\hline Z2 & $78.63 \pm 6.02$ & $77.60 \pm 5.37$ & 0.486 \\
\hline Z3 & $77.23 \pm 6.34$ & $74.80 \pm 5.76$ & 0.126 \\
\hline Z4 & $75.93 \pm 5.68$ & $98.26 \pm 6.29$ & $<0.001$ \\
\hline Z5 & $74.53 \pm 6.12$ & $96.73 \pm 6.20$ & $<0.001$ \\
\hline Z6 & $72.90 \pm 6.50$ & $93.60 \pm 5.97$ & $<0.001$ \\
\hline Z7 & $72.63 \pm 7.09$ & $91.50 \pm 5.47$ & $<0.001$ \\
\hline Z8 & $72.20 \pm 6.67$ & $88.10 \pm 6.06$ & $<0.001$ \\
\hline Z9 & $70.96 \pm 7.23$ & $84.46 \pm 6.53$ & $<0.001$ \\
\hline Z10 & $72.45 \pm 7.78$ & $85.55 \pm 6.63$ & $<0.001$ \\
\hline \multicolumn{4}{|c|}{ Table 2. Mean Values of Heart } \\
\hline \multicolumn{4}{|c}{ Rate \pm S.D at different Intervals } \\
\hline
\end{tabular}

\begin{tabular}{|c|c|c|c|}
\hline \multirow{2}{*}{ SBP } & Group I (n = 30) & Group II (n = 30) & \multirow{2}{*}{ P value } \\
\cline { 2 - 3 } & Mean \pm S.D & Mean \pm S.D & \\
\hline Z0 & $128.0 \pm 8.07$ & $130 \pm 6.05$ & 0.143 \\
\hline Z1 & $127.9 \pm 6.15$ & $127 \pm 4.48$ & 0.264 \\
\hline Z2 & $129.7 \pm 9.21$ & $129.0 \pm 4.23$ & 0.680 \\
\hline Z3 & $120.0 \pm 10.17$ & $127.3 \pm 4.22$ & 0.001 \\
\hline Z4 & $112.8 \pm 10.45$ & $146.4 \pm 7.04$ & $<0.001$ \\
\hline Z5 & $109.9 \pm 7.64$ & $144.4 \pm 6.71$ & $<0.001$ \\
\hline Z6 & $105.6 \pm 8.74$ & $141.4 \pm 6.81$ & $<0.001$ \\
\hline Z7 & $102.4 \pm 8.83$ & $137.8 \pm 6.67$ & $<0.001$ \\
\hline Z8 & $102.8 \pm 8.85$ & $134.7 \pm 6.42$ & $<0.001$ \\
\hline Z9 & $100.7 \pm 10.27$ & $132.0 \pm 5.31$ & $<0.001$ \\
\hline Z10 & $99.8 \pm 9.58$ & $134.2 \pm 6.42$ & $<0.001$ \\
\hline \multicolumn{4}{|c|}{ Table 3. Mean Value Systolic Blood } \\
Pressure \pm S.D at different Intervals (mmHg) \\
\hline \multicolumn{4}{|c}{}
\end{tabular}




\begin{tabular}{|c|c|c|c|}
\hline \multirow{2}{*}{ DBP } & Group I (n = 30) & Group II (n = 30) & \multirow{2}{*}{ P value } \\
\cline { 2 - 4 } & Mean \pm S.D & Mean \pm S.D & \\
\hline $\mathrm{Z} 0$ & $79.9 \pm 5.45$ & $78.1 \pm 3.37$ & 0.122 \\
\hline $\mathrm{Z} 1$ & $79.2 \pm 4.66$ & $77.17 \pm 3.24$ & 0.054 \\
\hline $\mathrm{Z} 2$ & $79.6 \pm 6.83$ & $76.97 \pm 3.38$ & 0.073 \\
\hline $\mathrm{Z} 3$ & $75.1 \pm 6.21$ & $75.17 \pm 4.47$ & 0.962 \\
\hline $\mathrm{Z} 4$ & $71.7 \pm 6.27$ & $93.97 \pm 5.86$ & $<0.001$ \\
\hline $\mathrm{Z} 5$ & $70.4 \pm 5.20$ & $91.80 \pm 5.09$ & $<0.001$ \\
\hline $\mathrm{Z} 6$ & $67.1 \pm 6.44$ & $88.90 \pm 4.75$ & $<0.001$ \\
\hline $\mathrm{Z} 7$ & $66.2 \pm 6.34$ & $88.90 \pm 4.75$ & $<0.001$ \\
\hline $\mathrm{Z} 8$ & $66.4 \pm 7.62$ & $86.30 \pm 5.18$ & $<0.001$ \\
\hline $\mathrm{Z} 9$ & $65.8 \pm 8.28$ & $83.37 \pm 5.09$ & $<0.001$ \\
\hline $\mathrm{Z} 10$ & $64 \pm 8.26$ & $84.54 \pm 6.07$ & $<0.001$ \\
\hline Table 4. Mean Value of Diastolic Blood Pressure \\
at different Intervals in Two Groups (mmHg) \\
\hline \multicolumn{4}{|c}{}
\end{tabular}

\begin{tabular}{|c|c|c|c|}
\hline \multirow{2}{*}{ MAP } & Group I (n = 30) & Group II (n = 30) & \multirow{2}{*}{ P value } \\
\cline { 2 - 4 } & Mean \pm S.D & Mean \pm S.D & \\
\hline $\mathrm{Z} 0$ & $69.53 \pm 4.24$ & $69.60 \pm 2.49$ & 0.931 \\
\hline $\mathrm{Z} 1$ & $69.93 \pm 2.81$ & $68.90 \pm 1.90$ & 0.101 \\
\hline $\mathrm{Z} 2$ & $70.67 \pm 4.37$ & $68.66 \pm 1.96$ & 0.075 \\
\hline $\mathrm{Z} 3$ & $66.38 \pm 3.94$ & $67.37 \pm 2.43$ & 0.247 \\
\hline $\mathrm{Z} 4$ & $62.44 \pm 4.42$ & $80.14 \pm 3.82$ & $<0.001$ \\
\hline $\mathrm{Z} 5$ & $61.0 \pm 3.76$ & $78.73 \pm 3.39$ & $<0.001$ \\
\hline $\mathrm{Z} 6$ & $58.58 \pm 4.51$ & $76.76 \pm 3.26$ & $<0.001$ \\
\hline $\mathrm{Z} 7$ & $57.07 \pm 4.46$ & $74.70 \pm 3.48$ & $<0.001$ \\
\hline $\mathrm{Z} 8$ & $57.02 \pm 4.79$ & $72.67 \pm 3.46$ & $<0.001$ \\
\hline $\mathrm{Z} 9$ & $56.39 \pm 5.56$ & $70.89 \pm 3.16$ & $<0.001$ \\
\hline $\mathrm{Z} 10$ & $56.18 \pm 4.88$ & $71.76 \pm 4.12$ & $<0.001$ \\
\hline \multicolumn{3}{|c|}{$\begin{array}{c}\text { Table 5. Value of Mean Arterial Pressure } \\
\text { in both Groups at different Intervals }\end{array}$} \\
\hline \multicolumn{3}{|c}{} \\
\hline
\end{tabular}

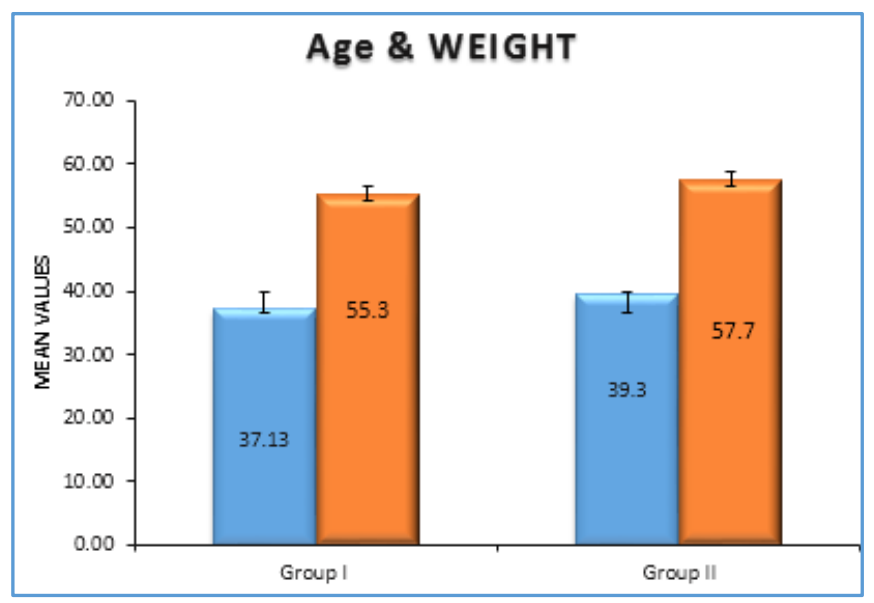

Figure 1. Demographic Characteristics of Two Groups

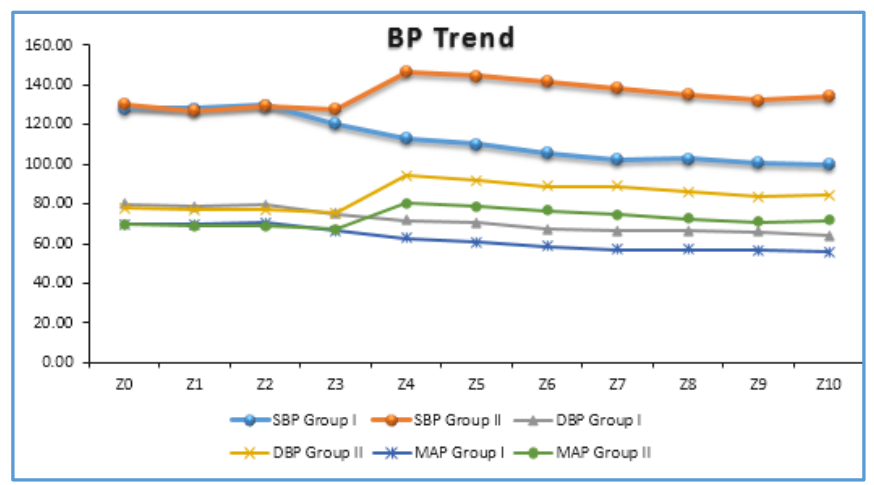

Figure 2. Systolic, Diastolic and Mean Arterial Pressures of Two Groups

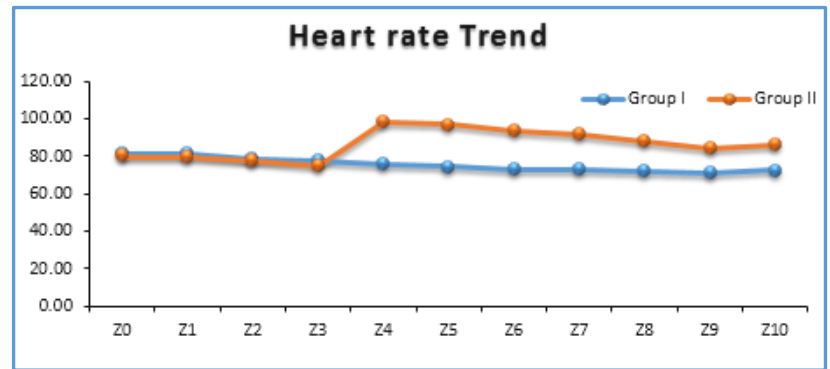

Figure 3. Heart Rate of Two Groups

\section{DISCUSSION}

Laryngoscopy and intubation evoke intense sympathoadrenal response causing tachycardia and hypertension. ${ }^{2}$ This response at times can prove deleterious in patients with coronary artery disease and diminished cardiac reserve as it can cause cardiac failure, myocardial ischaemia, ventricular dysrhythmias and stroke.13,4 Clonidine attenuates the pressor response by decreasing sympathetic outflow from CNS. In addition, clonidine also affects the functioning of potassium channels in CNS. This may be responsible for decrease in anaesthetic requirement. ${ }^{7}$ Sedation and anxiolysis caused by clonidine is mediated by its action on locus coeruleus. The inhibitory action on pre- and post-synaptic receptors at spinal and supraspinal level is responsible/contributes for its analgesic effects. The advantage of intravenous clonidine over oral clonidine is that it can be administered as infusion in preoperative period and effect is seen within 15 to 20 minutes as the distribution half-life of IV clonidine is approx. 11 mins and time to peak effect is 15 mins. ${ }^{10}$

Researchers have evaluated IV clonidine as premedicant, Wright PMC et al, Carabine UA et al, Leslie $\mathrm{K}$ et al, Zalunardo MP et al, Altan A et al have used clonidine infusion 15 mins before induction ${ }^{11,12,13}$ Carabine et al demonstrated that 1.25 $\mathrm{mcg} / \mathrm{kg}$ clonidine IV bolus 15 mins prior to induction of anaesthesia attenuated the pressor response to laryngoscopy and intubation in ASA I patients; however, Wright et al observed that $1.25 \mathrm{mcg} / \mathrm{kg}$ clonidine IV was not effective in suppressing the pressor response under similar conditions. In another study by Kulka $\mathrm{P}$ et al, it was observed that clonidine in doses less than $2 \mathrm{mcg} / \mathrm{kg}$ IV did not significantly attenuate pressor response. In same study, authors found that $4 \mathrm{mcg} / \mathrm{kg}$ clonidine IV was equally effective in suppressing the pressor response as $6 \mathrm{mcg} / \mathrm{kg}$.

Doses above $5 \mathrm{mcg} / \mathrm{kg}$ clonidine can cause hypertension due to peripheral alpha receptor stimulation. Keeping all this in view and looking at the results of such studies, we chose a dose of $3 \mathrm{mcg} / \mathrm{kg}$ of IV clonidine for our study. ${ }^{12}$

In our study, clonidine has shown anaesthetic agent sparing effect, which can be explained by its action on various receptors at spinal and supraspinal level.

In present study, we used monitoring of haemodynamic variables and lack of verbal response to determine the induction dose of propofol. Monitors such as BIS, which correlate with blood concentration of propofol and state of consciousness would have provided accurate results.

The potentially beneficial anaesthetic sparing effect of alpha- 2 agonists may be negated by bradycardia and hypotension. 
In this study patients receiving clonidine exhibited a significant reduction in heart rate and MAP, but did not develop bradycardia $(\mathrm{HR}<60)$ and hypotension (MAP < 50).

This could probably be explained by ASA I and II physical status of patients and use of lower doses of clonidine.

In conclusion premedication with $3 \mathrm{mcg} / \mathrm{kg}$ IV clonidine prevents haemodynamic response during laryngoscopy and intubation and significantly reduces propofol $14,15,16$ requirements for induction of anaesthesia in healthy subjects without inducing adverse effects on haemodynamic stability.

\section{REFERENCES}

[1] Fox EJ, Sklar GS, Hill CH, et al. Complication related to pressor response to endotracheal intubation. Anaesthesiology 1977;47(6):524-5.

[2] Russel WJ, Morris RG, Frewein DB, et al. Changes in plasma catecholamines concetrations during endotracheal intubation. Br J Anaesth 1981;53(8):8379.

[3] Forbes AM, Dally FG. Acute hypertension during induction of anesthesia and endotracheal intubation. Br J Anaesth 1970;42(7):618-24.

[4] Katz RL, Bigger JT. Cardiac arrhythmias during anesthesia and operation. Anesthesiology 1970;33(2):193-213.

[5] King BD, Harris LC, Greifenstein FE, et al. Reflex circulatory response to direct laryngoscopy and tracheal intubation performed during general anesthesia. Anesthesiology 1951;12(5):556-66.

[6] Stoelting RK, Dierdorf SF. Anesthesia and coexisting diseases. $4^{\text {th }}$ edn. Philadelphia: Churchill Livingstone 2002:105-29.

[7] Dollery CT, Davis et al. Clinical pharmacology and pharmacokinetics of clonidine. Clin pharmacol and Ther 1976;19(1):11-7.
[8] Ghignone M, Quintin L, Duke PC, et al. Effects of clonidine on narcotic requirements and hemodynamic responses during induction of fentanyl anesthesia and endotracheal intubation. Anesthesiology 1986;64(1):36-42.

[9] Fehr SB, Zalunardo MP, Seifert B, et al. Clonidine decreases propofol requirements during anesthesia: effects on bispectral index. $\mathrm{Br} \mathrm{J}$ Anaesth 2000;86(3):627-32.

[10] Davies DS, Wing AM, Reid JL, et al. Pharmacokinetics and concentration-effects relationships of intravenous and oral clonidine. Clin Pharmacol Ther 1977;21(5):593-601.

[11] Carabine UA, Wright PM, Moore J. Preanesthetic medication with clonidine: a dose response study. $\mathrm{Br} J$ Anaesth 1991;67(1):79-83.

[12] Kulka PJ, Tryba M, Zenz M, et al. Dose response effects of intravenous clonidine on stress response during induction of anesthesia in coronary artery bypass graft patients. Anesth Analg 1995;80(2):263-8.

[13] Altan A, Turgut N, Yildiz F, et al. Effects of magnesium sulphate and clonidine on propofol consumption, hemodynamics and postoperative recovery. $\mathrm{Br} \mathrm{J}$ Anaesth 2005;94(4):438-41.

[14] Yun MJ. Effects of intravenous clonidine premedication on pediatric adenotonsillectomy. Korean J Anesthesiol 2003;45(6):715-19.

[15] Zalundro MP, Serafino D, Szello P, et al. Preoperative clonidine blunts hyperadrenergic and hyperdynamic responses to prolonged tourniquet pressure during general anesthesia. Anesth Analg 2002;94(3):615-618.

[16] Marinangeli F, Cocco C, Ciccozzi A, et al. Hemodynamic effects of intravenous clonidine on propofol or thiopental induction. Act Anaesthesiol Scand 2000;44(2):150-6. 